\title{
PAÍS SECRETO DE JUAN MANUEL ROCA: PARA UNA POÉTICA DE LA VIOLENCIA ${ }^{1}$
}

\author{
Juan Carlos Galeano*
}

\author{
"Agua y viento han corrido agitando cafetales \\ Y el sol no seca aún el rojo de los aljibes, \\ ¿Dónde anda la voz de los ausentes? \\ De "País de aus entes"
}

(País secreto 57)

En la segunda mitad del siglo XX la violencia y el terror han imperado en Latinoamérica hasta el grado de propiciar, entre sus varias representaciones artísticas, el incremento de un modo poético comprometido o "engagé" (para utilizar dos de sus muchos nombres). Este tipo de lírica que ganó carta de identidad con la toma de conciencia de poetas vanguardistas como Neruda y Vallejo, ${ }^{3}$ en Colombia habría de tomar fuerza des de los años cuarenta, durante la época "la violencia" y los cidos que siguieron de la misma. A partir de dicho periodo, y después, reconocidos poetas colombianos han respondido con variantes poéticas solidarias frente a la violencia gubernamental y civil. ${ }^{4}$ En este artículo se estudiará una poesía más actual de compromiso, presente en Juan Manuel Roca, ${ }^{5}$ conocido por su obra "de imágenes originales de plena estampa surrealista en que lo cotidiano y la ensoñación se confluyen en cuadros líricos de panoramas nocturnos" (AsIstrum 68), quien se desvía de su es tética establecida para adoptar en País secreto (1987) un modo y contenidos líricos más históricos.

\footnotetext{
${ }^{1}$ Valga aclarar que el término violencia utilizado en este artículo es una categoría mucho más amplia que aquél de "la violencia", usando para describir el en frentamiento entre los miembros de los partidos liberal y conservador especialmente en las décadas de los años 40 y 50 . El término, referido a los años 80, enmarca una dinámica relacional de violencias con nuevos actores y escenarios, evidenciada en sus manifestaciones más sobresalientes por el enfrentamiento EstadoGuerrilla, la presencia del paramilitarismo y el narcotráfico. Para una discusión actualizada sobre el uso de este término, véase el artículo de Ortiz Sarmiento (1:371-374).
}

* Profesor Florida State University

${ }^{2}$ Frederic Murray menciona lagunos de los quince adjetivos con los que, según él, se nombra a este tipo de poesía en términos de su referencialidad. En cuanto a la forma, los divide en categorías de antipoesía y poesía exteriorista (17).

3 Alberto Julián Pérez propone un ordenamiento de las diferentes tendencias post-vanguardistas de la poesía latinoamericana. Señala el papel decisivo jugado por Neruda y Vallejo, quienes rompieron con la tradición vanguardista hermética reaccionando de manera solidaria con un modo poético histórico y social ante las crisis internacionales y la Guerra deEspaña.

${ }^{4}$ Aludo principalmente a los poemas referenciales de los poetas de Mito y aquéllos de Nadaísmo. Para un estudio e información bibliográfica sobre ciertas variantes de poesía "egagé", escritas en colombia durante los años 50y 60, pueden consultarse los capítulos III, IV y V de mi libro Polen y escopetas.

${ }^{5}$ Juan Manuel Roca (1946). De sus muchas publicaciones literarias y de poesía, sus poemarios más conocidos son Memoria del Agua (1973), Luna de ciegos (1975), Los ladrones nocturnos (1977), Señal de cuervos (1979), Fabulario real (1980), País secreto (dos ediciones, 1987, 1988), Ciudadano de la noche (1989), Pavana con el diablo (1990). Por su poesía, entre otras distinciones, ha recibido El Premio Nacional de Poesía Eduardo Cote Lamus (1975) y el Premio Nacional de Poesía Universidad de Antioquia (1979); en periodismo ha recibido El Premio de Periodismo Simón bolívar (1993), entre otros. 
Me propongo articular la materia histórica de la violencia colombiana de los años 80 con la actitud política y civil de Roca, y su visión poética frente a las penurias de la historia. Trataré de demostrar cómo Roca, poseedor de un lenguaje metafórico de gran polisemia en su obra general y en este libro, logra construir en País secreto un paradigma estético mayoritario de modos líricos fluctuantes que van de imágenes realistas a las metáforas de corte surrealista y expresionista características del estilo de su poesía previa. ${ }^{6}$

Asimismo, a pesar de la posición solidaria general del autor con las mayorías históricas, demostrada en casi la totalidad de sus poemas de País secreto, trato de develar momentos de una actitud crítica suya hacia las víctimas de la violencia, actores también responsables durante los mencionados años de inestabilidad política y cris is social del País.

Se advierten en País secreto principalmente las contigencias históricas de finales de los 70 y luego de los 80 que afectaron la vida de los colombianos, manifestadas en la represión policiva, debido al enfrentamiento del sistema de dominación con los grupos guerrilleros y disidentes, a la escalada del narcotráfico y al acoso de las facciones paramilitares en las zonas rurales. ${ }^{8}$ Asocia Roca en sus declaraciones civiles, su poética a una visión voluntarista y crítica de la sociedad de los años 80 en que hace responsable a las clases dirigentes actoras de la violencia a través de sus líderes estatales: "con Turbay, incremento de las torturas, con Belisario de las desapariciones y con Barco de la guerra sucia" (Rodríguez Núñez 7), ${ }^{9}$ como si en País secreto el poeta se hubiera vuelto "un tipo de amanuense, ya no en este caso de los dioses, sino un amanuense de su entorno y de su pueblo" (Alstrum 71). Un modo paradigmático comprometido que no podemos dejar de identificar con otras bien conocidas variantes históricas de la poesía latinoam ricana a partir de la segunda mitad del siglo. ${ }^{10}$ Inaugura Roca en su libro un interés ciudadano fundamental de poeta insertado en la historia con el tipo de es critura que al decir de Murray:

Es enfática en sus denuncias de los males de la comunidad humana de nuestra época. La poesía social y de protesta contemporánea de Latinoamérica refleja no

\footnotetext{
${ }^{6}$ Hacen falta estudios más detallados y totalizantes de su obra. No existen más que entrevistas y algunas acertadas notas y reseñas sobre sus poemarios, escritas en su mayoría por poetas y críticos colombianos. ${ }^{7}$ Estos años también enmarcan la escritura de poetas contemporáneos de Roca. Para introducciones generales sobre la
poesía roca y de los otros poetas colombianos de la "Generación sin nombre" que siguió a la poesía nadaísta, pueden
consultarse los artículo de Carranza, Jaramillo, Cobo Borda, Cote, Araujo, entre otros.

${ }^{8}$ Para una noción de los principales factores de violencia durante la década de los 80 , y bibliografia relativamente actualizada de la misma, véanse los estudios recientes de Bushnell y Palacios; asimismo, el ensayo de Heinz. Para una versión sucinta sobre el carácter multifacético y caótico de laviolencia, véase la entrevista-texto de Morales Benítez.

${ }^{9}$ De modo explícito, en otras entrevistas, el poeta mismo reitera esta afirmación sobre el origen de su libro:

"De los últimos tres gobiernos de nuestro País, en donde los fenómenos de tortura, de desaparecidos, de guerra sucia, se han hecho cada vez más una presencia cotidiana, irónicamente podría señalar que ha sido el triste sustento del material para estos poemas. País secreto es un intento de ejercer la libertad de pensamiento desde el poema” (Bernal Arroyabe9).

${ }^{10}$ Me refiero a la poesía comprometida de poetas como Fayad Jamis, Ernesto Cardenal, Roque Dalton, Javier Heraud y otros. Se encuentran ejemplos de poemas comprometidos de estos autores en la antología de Ramiro Lagos. Para otras antologías depoesía social en Latinoamérica, pueden verse también los de fierro, Donoso Pareja y Márquez.
} 
sólo los males políticos, sino también los más obvios defectos económicos, sociales y morales que destruyen la vida en el mundo latinoamericano. Y por inferencia, esta poesía se ocupa de señalar también aquellos defectos de quienes generan esos males y miserias en aras de llevar a cabo de manera egoísta sus propósitos políticos y económicos. En este tipo de poesía se condenan todos los "vicios de mundo modemo", como lo dice el poeta chileno Nicanor Parra a través de es te título de un poema suyo memorable. (17, traducción mía).

Casi desde la entrada de País secreto, la His toria irrumpe cuando el poeta se erige para denunciar los males de su entorno. En "Una carta rumbo a Gales", usando el mecanismo retórico de un cronista de su entomo, registra los eventos del País y su propio sentir:

Me pregunta

Qué siento en estos días a este lado del mar.

Un alfileteo en el cuerpo,

La luz de un frenocomio

Que llega serena a entibiar

Las más profundas heridas

Nacidas de un poblado de días incoloros.

...

La entero a usted:

Aquí hay palmeras cantoras

Pero también hay hombres torturados.

(País 11-12)

En este poema, que evoca "La epístola a Madame Lugones" de Rubén Darío (Arévalo 63), observamos sus articulaciones del movimiento pendular de imágenes que nos llevan de un lenguaje llano, como éste de la pregunta imaginaria, al modo de alta elaboración e independencia metafórica que luego se atenúa en la imagen de "Las más profundas heridas" (un verso más referencia y accesible) para seguir a otra imagen más autónoma en "nacidas de un poblado de días incoloros", y así sucesivamente. Aunque la idios incrasia metafórica de Roca "de plena estampa surrealista en que lo cotidiano y la ensoñación confluyen en cuadros líricos de panoramas noctumos", se impone en la totalidad del libro, el vaivén de modos poéticos que acabamos de advertir se halla presente en muchos poemas del texto (unas veces al interior de un mismo poema, otras, de un poema a otro). Así, articulando su discurso poético a través de los modos descritos anteriomente, Roca se abre a la posibilidad de llegar a un público mayoritario. En la teleología de tal actitud, pensamos, la factura poética de Roca parece coincidir con los planteamientos de Miloszen el sentido de que el poeta logra comunicarse gracias a que el lenguaje "recobra sus funciones más elementales y se hace otra vez instrumento para servir un propósito; ... el lenguaje debe nombrar la realidad, la cual existe objetivamente, masivamente y tangible y terrible en su naturaleza concreta" (80, traducción mía). 
Queriendo registrar quizás una larga tradición de dictaduras, violaciones de los derechos humanos y persecuciones políticas en Colombia, y con su deseo de "señalar los fantasmas del miedo, del temor enquistado en la vida cotidiana del hombre colombiano" (Villegas 136), adivinamos la represión y amenaza constante a través de sus versos cuando nos dice: "Para tu corazón bisies to acostumbrado a narrar / La caza de brujas en palacios" (País 62). Asimismo logra transmitirnos la zozobra causada por el asalto a las moradas de los ciudadanos por parte de las fuerzas secretas del estado "Con gabanes abultados por la escuadra de una lugger", quienes allanan en las madrugadas la tranquilidad. Evidencian también sus denuncias las persecuciones contra muchos artis tas durante los años 80: "Y en la noche mientras leída a mis viejos poetas / enlunados / una legión de sombras ha roto mi ventana" (País 19). Luego, con un lenguaje unívoco, habla de su País como "un lugar cuyos inciertos habitantes / Podemos desaparecer definitiva o temporalmente / Hasta ser encontrados al borde del camino" (País 22): añade el as edio de los nuevos ciclos de violencia en las zonas rurales donde "hay en la noche de los campos un árbol de / puñales" (País 14), mostrándonos en este último verso un estilo metafórico de gran poder evocativo y calidad expresionista.

Roca para quien el poeta tiene que ser "una pers ona que necesariamente tiene que estar ligada a una lucha de tipo colectivo, no de tipo individual" (Alstrum 71), parece sentir en País secreto una fascinación por la posibilidad de que la poesía pueda hacer mella en el tiempo de la historia mediante la exposición de los "vicios" y males de la sociedad. Aunque él no se plantea en este libro ninguna actitud partidista específica con alguna facción política colombiana de izquierda, sí asociamos su posición con aquélla vista en Latinoamérica en que la poesía ha querido ser artífice de esa "identificación colectiva que conduce a la solidaridad" (Bornstein 34). Y dicha actitud suya revolucionaria y social, no sólo es propia de nuestro tiempo sino también común a otras épocas; no muy diferente a la fascinación que han sentido los poetas de la Modernidad desde el Romanticismo hasta la Vanguardia por las revoluciones. Este es un hechizo, según Octavio Paz, fundado sobre la base de que las revoluciones son una promesa de vuelta a la felicidad en la sociedad de hemanos. ${ }^{11}$

Una filosofía de humanismo marxista, lo hemos vis to, pemea el libro proveyendo una base ideológica mediante la cual el autor ${ }^{12}$ se plantea a veces la génesis de la violencia en una sociedad clasista: "Sonó en la noche un disparo... / Y un hombre, a la mañana siguiente entró al olvido ... / La mano del poder, enguantada y lejana, lleva una copa hasta sus labios" (País 76). Mas, por tales momentos en su libro, no se debe creer que Roca exclusiviza el origen de la violencia en los grupos de detentan el poder. La degradación moral del País y la presencia de actores de la violencia ocurren en todos los lugares de la vida. En los versos

\footnotetext{
${ }^{11}$ En Los hijos del limo Paz nos dice sobre esta relación problemática entre poesía y revolución, entre mito e historia. Apoya su crítica con el registro de los varios intentos desafortunados de comunión, de los poetas románticos durante la Revolución Francesa y posteriormente de los vanguardistas con la Revolución Rusa. Véanse especialmente sus capítulos III y VI.

${ }^{12}$ Relacionamos este hecho con otras declaraciones del autor a favor de una estética comprometida:

"Creo que el verdadero poeta debe tocar todas las piezas del teclado y una de esas piezas importantes es la política ... Hay que ligarla poesía a la política” (Melo y Bernal Arroyabe 15).
} 
anteriores, donde señala la realidad con un lenguaje directo de modo unívoco e histórico, él no nos traza directrices revolucionarias; él sabe que las lacras de la nación también encuentran su generación y manifestaciones ${ }^{13}$ en los grupos subordinados de la sociedad:

Los barrios de la pillería. Las tres jornadas de sus manos:

El alba táctil en las caderas de una mujer desaliñada. El mediodía entrando en la penumbra de los bolsos, en la pequeña noche de los gabanes: febril homigueo de los dedos del hampa. La apostada noche en los recodos donde el revólver le da voz a los cobardes. (País 73).

Por otra parte, la pobreza le merece una expresión de maravilla terrible. En su poema "En la ruta del agua" ve la miseria de los habitantes del río Magdalena en "El planisferio en los ojos de sus hijas", extendiéndose su visión sobre la desesperación humana a los estados espirituales situados más allá de su penuria material: "Los mendigos enseñan su costillar: La jaula ósea / Donde todo el día picotea el corazón" (País 38). Observamos en estos versos, al igual que en otros textos de País secreto, al poeta yendo de su regis tro verbal explícito de la realidad en que "los mendigos enseñan su costillar" al gran salto metafórico expresionista, ${ }^{14}$ sugerente de complejidades síquicas "Donde todo el día picotea el Corazón".

Siguiendo la premisa de las declaraciones civiles del autor sobre los eventos políticos y sociales de los años 80 que alimentan la materia poética de País secreto, las desapariciones y las muertes también lo tocan en la persona de sus amigos. Su poesía nos dice de su dolor de "lo que es vivir / Entre lunas de ayer, muertos y despojos" (País 12); y por las muertes misteriosas "Hay un poblado de hombres desaparecidos" (País 19). Aspecto que se incrementa en su poema "Violín de los aus entes" 15 casi hasta un planto personal, especialmente cuando acuden a la memoria estos "amigos muertos en la guerra del País del desconsuelo..." "Como el que tiene más amigos en las tumbas que en los bares". No halla otra salida que terminar el poema mediante un rasgón expresionista: "baila el corazón con el roto violín de los ausentes" (País 70).

La realidad perturbadora y los desastres de la patria parecen tener sus efectos y correlato en los estados síquicos del poeta quien transporta sus estados

\footnotetext{
${ }^{13}$ Se adivina también en esta viñeta el micro-cosmos que en los mismos años 80 tuvo su excelente realización en el cine colombiano con la película neorrealista Rodrigo D. Del poeta Víctor Manuel Gaviria (Cobo 248-249). En Roca, el tratamiento de este contexto, se logra mejor posteriormente en su poema "Monólogo de un pandillero", donde expresa a una juventud delincuente:

"Insegura de no estar aferrada a la cacha de un revólver" (Luna223).

${ }^{14}$ No es dificil asociar esta imagen donde "picotea el corazón” con la poética expresionista del siglo XX que Furness describe como: "Un encantamiento mágico que debe inducir al lector a descubrir por sí mismo lo que el poeta ha experimentado y desea expresar" (20).

${ }^{15}$ El carácter fatídico de su poemario se puede inferir desde los títulos de los poemas. Nada más a partir de dichos títulos se podría construir toda una sintomatología de la violencia de la época: "Parte de guerra", "Lista negra", "Botellas de náufrago", "De las peores leyendas", "Carta del incierto", “En la ruta del agua", "Los muros de la noche”, "País de ausentes", "Toque dequeda".
} 
espirituales al mundo del hablante lírico. Los intentos de paz entre el Estado y las fuerzas guerrilleras hacia mediados de los años 80 fracasan, y se incrementa la inestabilidad con las nuevas violencias generadas por las bandas de narcotraficantes (Bushnell 253-568). El País no mejora y el sujeto lírico nos dice de una "bandera blanca sobre lagos de sangre" (País 22), revelándonos con la anteriormetáfora de surrealismo expresionista su pesimismo casi apocalíptico. La nación se hunde en el fracaso y "es frecuente escuchar en las calles y en los bares - A las gentes que hablan d abandonar un País como un / barco que naufraga" (País 19). Nos dirá después con un lenguaje suyo más austero, ${ }^{16}$ pero no menos revelador de su desconsuelo, que has ta él mismo naufraga, y sus gritos sólo son:

Mensajes enviado por un náufrago,

Botellas con gritos pobremente escritos

Que acaso vayan desde el mar de los silencios

A las playas del olvido.

Pero he aquí que lanzo una botella y otra,

Y una última hab itada pormis miedos. (País 62)

Quizás, a veces, la solución sea no existir; es lo que parece decirnos en otro momento de su libro, en su poema "Luna negra de 1930", donde la fecha le proporciona un paisaje temporal que le permite imaginar, no sin sarcasmo, una falsa felicidad. Mas, sabemos, es sólo una máscara, pues la verdad del País encierra "Batidas callejeras / Requisas a nombre de nadie / Oscura cetrería en todos los umbrales" y un luto abrumador:

Luna negra vestida de azabache

Mi País, noche emboscada (País 40)

Y la luna que en otros poemarios bañara con cierta luz mágica y positiva sus poemas ("La luna agita / el agua en los cántaros sonoros" [Luna 19], sufre aquí su metamorfosis hacia una visión de negatividad casi arquetípica. A la salida del poema, la "luna" con un brillo luctuoso acompaña e ilumina como un sol negro el sentido paisaje espiritual que Roca desea compartir con nos otros.

Pero la naturaleza dual ${ }^{17}$ de País secreto también conlleva un principio de supervivencia a pesar de las realidades de miseria material y humana que vive el País. Su poesía de naturaleza "trágica" y "festiva", según dijera el crítico cubano

\footnotetext{
${ }^{16}$ Aunque la poesía de Roca en País secreto respira una voluntad social, no me parecería adecuado asociar ésta con una poesía estrictamente referencial y partisana. Michael Hamburger habla de una "nueva austeridad" para adjetivar el carácter de los textos poéticos que aunque encarnen preocupaciones sociales en sus gestos e imágenes dominan menos los sucesos registrados que la reacción del poeta ante ellos" (226). Para información bibliográfica sobre el tipo de poesía partidista de tono didáctico que se dio en Colombia y en España durante "la violencia" y la Guerra Civil Española. (Consúltese el capítulo II de mi libro Polen...)

${ }^{17}$ Cobo Borda utiliza este adjetivo "dual" para caracterizar su poética al decir que Roca "ha logrado compaginar su devoción por un romanticismo surrealista, de imágenes nocturnas, con el propósito de dibujar un País dual y secreto" (248).
} 
Manuel Gayol "se proyecta como un grito de ansias por vivir en un mundo mejor; es la catars is por liberarse de la impotencia" (2).

Existen otras realidades que sobreviven y salvan. Paralela a esa mayoría abrumadora de versos aciagos de "Bastidas callejeras / Requisas a nombre de nadie", existe una música de contrapunto, su verdad de un País "secreto" con fuerzas y posibilidades es pirituales que ni la violencia ni el miedo pueden acallar:

Aquí hay cielos ab solutamente desnudos

Y mujeres encorvadas al pedal de la Singer

Que hubieran podido llegar en su loco pedaleo

Hasta Java y Burdeos,

Hasta el Nepal y su pueb lito de Gales,

Donde supongo que beb ía sombras su querido

Dylan Thomas.

Las mujeres de este País son capaces

De coserle un botón al viento,

De vestirlo de organista. (País 12).

A la dureza, la capacidad para soñar. El potencial metafórico autónomo de Roca se dispara hacia regiones de una mitología surrealista en el presente que le sirve, según él mismo, "de confrontación con una realidad absolutamente pedestre y violente como es la realidad nues tra". No en balde ha dicho en sus declaraciones personales que "por medio de la ensoñación se puede llegar a imágenes que tienen el poder de crear otra realidad paralela a la que vive uno" (Alstrum 69). Con estas premisas, reveladoras de una posición verdaderamente más poética que política, el poeta es capaz de construir un mundo de esperanza para salvarse del pesimismo total. Mejor es creer en el tiempo de la esperanza. Un tiempo que, según el poeta, ha existido siempre en Colombia, donde "un contrabando de sueños cruza todas las noches sus fronteras" (País 63), como lo afima en su texto "País secreto" (que además de título a su libro). Porque en las inflexiones de ese mismo tiempo y espacio histórico colombiano aunque "un puñado de muertos nos gobierne, gozamos del rezo solar en un vaso de vino" (País 50).

Entre la poesía y la historia. País secreto es un texto que también revela una solidaridad con aquéllos que pertenecen a órdenes culturales y sociales silenciados y relegados a un segundo plano en la "historia oficial". Dichas alteridades, acalladas desde las primeras imposiciones culturales de los españoles, subyacen como potencialidades transcendentes. Él los restaura y están allí en su poema "País de fuego", para venir a salvarnos del presente injuriado: "Para tu brumoso pasado de talismán y cerbatanas / Y el pemanente golpear de rebelión en tus venas...", "Esta noche bailo cosido a la piel de tus guerreros" (País 62). También, en "Al regreso de la fiesta", otros órdenes sociales ofendidos construyen su propio tiempo mítico con el presente: "En aquellos barrios populosos / las muchachas repartían / la dulce fruta de su habla" (País 48). 
Pero todas las certezas, directas o inferidas, sobre la solidaridad de Roca con grupos subordinados a la explotación económica y sometidos a la exclusión cultural y política ejemplificada por nosotros, no quieren decirnos que él es un poeta comprometido ciegamente con las posibilidades y realizaciones políticas del "pueblo". La falibilidad humana habita en todos los órdenes. En este libro también se evidencia su posición de crítico muy cáustico. "Panfletos", por ejemplo, es un poema que nos informa de esa calidad de desilusión frente a la apatía de los habitantes de su País. Casi generacional, pues alrededor de este poema se podría identificar muchos jóvenes latinoamericanos progresistas por cuando el texto dice de una nostalgia por el tiempo de comunión y experiencia poética a través de la Revolución, de un tiempo en que también él se sentía y "fingía un pequeño Rambaud caminando entre los rieles de una antigua estación, o entraba a saco contra una Bastilla inexistente". También él, en los témininos de ese encuentro de Revolución y poesía, podríamos inferir, tuvo la esperanza de ser partícipe de los cambios para lograr una sociedad de fraternidad y de justicia en su País: "En mi sueño era de ver nuevamente la Comuna humeante y hombres presurosos repartiendo boletines de otros sueños. Comuneros del País de la guadua, levantiscos hombres de piel enamorada". Pero tal deseo de una utopía paralela (que propone frente a las represiones, torturas, muertes, y las mil y una violencias) parece fracasar por culpa de la indolencia de esa Colombia que él llama en este poema "el País de los idiotas", a cuyas gentes él temina diciéndole con ironía: "sigan dumiendo, almas de Dios, felices sueños" (País 71). ${ }^{18} \mathrm{Si}$ antes hablábamos de una fascinación optimista de tradición romántica en roca y de su deseo de dejar su marca en el tiempo de la historia con una poesía solidaria, vemos aquí, casi a la salida del libro, la desilusión de esta dimensión existencial del poeta. Lejos del maniqueísmo, en su conciencia crítica, nos parece ver, existe de modo implícito su visión de cierto fracaso de las posibilidades de transformación de la historia por el fallo de los sectores subordinados y excluidos de la sociedad con los cuales él se ha solidarizado a través de su libro. Este momento de nostalgia y desencanto, pensamos, trasunta una aspiración revolucionaria suya, pero la Revolución nunca llega. ${ }^{19}$

País secreto se da en la historia y contra los accidentes de la misma. Dentro de tal marco de circunstancias hemos identificado en los rasgos del discurso poético de Roca cierto dualismo a nivel formal a partir de una retónica directa y un modo poético más elaborado, la "otra voz", su discurso de metáforas reveladoras de lo fatídico. Ambos modos poéticos, y especialmente su combinación totalizante,

\footnotetext{
${ }^{18}$ Durante "la violencia", los poetas populares y algunos miembros de la generación de la revista Mito ofrecieron un tipo de arte las más veces didáctico y esperanzado, ya fuera por su invitación a la lucha, ya a través de imágenes arquetípicas de fecundación de la tierra porla sangre de las víctimas. Una visión voluntarista y polarizada en que, hasta donde se sabe, los poetas en ningún momento ejercen una crítica tan cáustica sobre "el pueblo" como lo hace Roca en su poema "Panfletos".

${ }^{19}$ Valga aclarar aquí que en "Panfletos" el desencanto de Roca se debe a la indiferencia de las gentes de su País. Es por culpa de esas gentes que el momento revolucionario nunca sucede. Él, a diferencia de los poetas románticos y vanguardistas fascinados con las posibilidades poéticas de la Revolución y frustrados por la cerrazón de los líderes de la misma, no ve la celebración del momento revolucionario en Colombia. Por otro lado, la visión de los Nadaístas sobre la

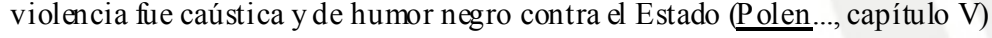


comparten con los lectores no sólo una visión y sentir del poeta frente al sufrimiento humano causado por la violencia, sino también, tal el caso en algunos de sus poemas, su optimismo. Gracias a dichos modos, su voz lírica también nos dice sobre las complejidades y polaridades humanas que rigen las inflexiones del tiempo histórico (de victimarios y de víctimas) en donde su poesía, sin abandonar su posición crítica en su función cognoscitiva, favorece su inclinación solidaria hacia las víctimas. Pero, afortunadamente, no es este favor revolucionario de determinismo semántico el que se impone en País secreto, sino más bien las imágenes más finas de su poética más reconocida. Tal discurso poético solvente en su representación de la violencia emparenta a Roca con otros poetas de la mejor poesía social latinoamericana y, por qué no decirlo, también con la tradición solidaria universal del siglo $X X$. En general, su compromiso, con el lenguaje y los problemas nacionales, se nos antoja, le justifican una relación con poetas como Yannis Ritsos y Aimé Césaire, por los que él mismo expresara admiración (Bernal Arroyabe 9). Roca pleno de poderes poéticos, señalados por nosotros a través de nuestro ensayo, es capaz d salirle al paso a la his toria, armado con sus metáforas capaces de provocar la catarsis, durante esta instancia desafortunada de amenaza y violencia con su "árbol de puñales". Pero no sólo su capacidad de servirnos de llanto y de conjuro ante la muerte, sino también su deseo de compartir cierto destino de esperanza. Porque a ese viento nefas to que recorre en los campos de la patria "agitando cafetales" el poeta le sale al paso, no con metáforas doloridas que producen el lloro catártico, sino con ese albur de supervivencia vitalista, de mujeres "capaces / de coserle un botón al viento / de vestirlo de organista", como nos dijera anteriormente en sus versos (memorables ya entre la poesía de su generación) de País secreto que hemos querido postular aquí como una de las variantes líricas de voluntad social más originales de la poesía colom biana.

\section{Bibliografía}

Alstrum, James. "Juan Manuel Roca y sus noctumos de ensueño, magia y violencia:" Revista de Estudios Colombianos. 2 (1987): 68-71.

Araujo, Helena. "Algunas post-nadaístas". Revista Iberoamericana 128-129 (1984):

Arévalo, Guillermo Alberto. "Roca atrapado en el aire". Folios Segunda Época 6 (1996): 62-64.

Bernal Arroyabe, Guillermo. "Juan Manuel Roca y el País secreto: Todas las piezas del teclado". El Espectador [Bogotá, Colombia] 13 de diciembre (1987): 7-9.

Bornstein, Miriam. "Introducción general a la nueva poesía sociopolítica hispanoamericana”. Casa de las Américas 143 (1984): 33-49.

Bushnell, David. The Making of Modern Colombia. A Nation in spite of Itself. Berkeley: Univers ity of California Press, 1993. 
Carranza, María Mercedes. "Poesía post-nadaísta". Revista Iberoamericana 128129 (1984): 799-819.

Cobo Borda, Juan Gustavo. "En un País de poetas, la tradición en crisis". Literatura colombiana hoy. Imaginación y barbarie. Ed. Karl Kohut. Frankfurt-Madrid: Universidad Católica de Eichs tatt, 1994. 239-264.

Cote Baraibar, Ramón. "Los últimos veinte años en la poesía colombiana." Insula. Agosto-Septiem te (1989): 43-44.

Donoso Pareja, Miguel. Ed. Poesía rebelde de América. México: Editorial Extemporáneos, 1971.

Fierro, Enrique. Ed. Antología de la poesía rebelde hispanoamericana. Montevideo: Ediciones de la Banda Oriental, 1967.

Furness, R. S., Expressionism. London: Methuen \& Co Ltda., 1973.

Galeano, Juan Carlos. Polen y escopetas. Santafé de Bogotá: Editorial Universidad Nacional, 1997.

Gayol Mecías, Manuel. "Juan Manuel Roca y la utopía posible”. (Texto inédito).

Hamburger, Michael. La verdad de la poesía. Tensiones de la poesía modema de Baudelaire a los años sesenta. Trad. De Miguel Ángel Flores y Mercedes Córdoba magro. México: Fondo de cultura económica, 1991.

Heinz, Wolfgang S. "Violencia política y cambio social en Colombia". Literatura colombiana hoy. Imaginación y barbarie. Ed. Kjarl Cohut. FrankfurtMadrid: Universidad Católica de Eichstatt, 1994.

Jaramillo, Samuel. "Cinco tendencias de la poesía post-nadaísta en Colombia". Eco 224 (1980); 371-393.

Márquez, Roberto. Ed. Latin American Revolutionary Poetry. New York: Monthly Review Press, 1974.

Melo, Luz Ángela y Guillermo Bernal Arroyabe. "La poesía como una vocación de imposibles". Casa de las Américas 175 (1989): 8-17.

Milosz, Czeslaw. The Witness of Poetry. Cambridge, Massachussetts: Harvard University Press, 1983.

Morales Benítez, Otto. "El proceso de la paz en Colombia: La lucha contra la violencia". (Entrevista con Raymond Williams y León Helguera). Violencia y literatura en Colombia. Ed. Jonathan Tittler. Madrid: Editorial Orígenes, 1989.

Murray, Frederic W. The Aesthetics of Contemporary Spanish American Social Protest Poetry. Lampeter, Wales Edwin Mellen Press, 1990.

Ortíz Sarmiento, Carlos Miguel. "Historiografía de la violencia". En La historia al final del milenio. 2 tomos. Ed. Bernardo Tovar Zambrano. Santafé de Bogotá: Editorial Universidad Nacional de Colombia, 1994. 1:372-431. 
Palacios, Marco. Entre la legitimidad y la violencia. Colombia 1875-1994. Bogotá: Grupo Editorial Noma, 1995.

Paz, Octavio. Los hijos del limo. Barcelona: Editorial Seix Barral, 1989.

Pérez, Alberto Julián. "La poesía postvanguardista en Hispanoamérica". Hispania 75 (1992): 50-59.

Roca, Juan Manuel. Luna de ciegos (obra poética 1973-1994). México: Editorial Joaquín Mórtiz, 1994.

--- País secreto. Bogotá: Ediciones el caballero Mateo, 1987.

Rodríguez Núñez, Víctor. "Juan Manuel Roca: La poesía es un oficio riesgoso". Nuevo amancer cultural. [Managua, Nicaragua], 288 de enero (1989): 7.

Villegas, Esmeralda. "La poesía es el mayor ejercicio de la liberta". Signo y Pensamiento. 15 (1989): 133-140. 